\title{
Teachers' Attitudes Towards English as Medium of Instruction
}

Krishna Kumar Khatri

\begin{abstract}
English as medium of Instruction (EMI) has been a genuine issue of discussion in today's pedagogical field among the concerned stakeholders including teachers. In this concern, a mixed method study entitled 'Attitudes of teachers towards using English as Medium of Instruction (EMI) in Public Secondary Schools of Ilam was attempted to explore the teachers' attitude towards using EMI in the public schools and challenges faced by them in course of adopting EMI. For this, twenty secondary level English teachers were accessed purposively and data were collected using questionnaire consisting of both close ended and open-ended questions. The results of the study revealed that teachers of public schools were found aware of the basic concept of the notion of English as a medium of instruction. They were found positive in implementing EMI in conducting their daily teaching and learning activities. The study also showed that teachers of secondary level have been facing different challenges in adopting EMI in the classroom like students'weak exposure to English, mother tongue interference, unresourceful schools and linguistic diversity in the class. The study recommended that there should be conducive and encouraging environment in the public schools for the teachers for adopting EMI in the class. The schools should be made resourceful and well equipped with modern technologies. Moreover, the teachers should be made sound with pedagogically and professionally.
\end{abstract}

Keywords: English as medium of instruction, English language, English language teaching

\section{Introduction}

English language has gained its status of global means of communication. Today, it has been playing the role of lingua franca among the people from dispersed and diversified linguistic and cultural background. English, nowadays, no longer remains the property of the English speaking countries like Britain, America and Australia. It has become an inclusive channel of communication in the field of education and commerce throughout the world. Regarding the remarkable position of the English language in the world, Phillipson (2007) writes:

English is now entrenched worldwide, as a result of British colonialism, international interdependence, 'revolutions' in technology, transport, communications and commerce and because English is the language of the USA, a major economic, political and military force in the contemporary world. It may not only Britain which has gravitated towards linguistic homogeneity, but the significant portion of entire world. (pp. 23-24)

From this, it can be inferred that English language has spread its coverage in almost all sectors and fields all around the world. It is not only the language of one specific land and territory. It has covered almost every space and portion of knowledge in the present day world.

Similarly, the English language has become the main source of gaining knowledge. For this, Crystal 1990, p.7) writes, “Textbooks on English these days regularly rehearse the litany of its achievements. It is 
the main language of the world's book newspaper and advertising". From Crystal's idea, it can be said that anyone who wants to gain knowledge of either of the fields should be competent in the English language. Moreover, English is the language of global importance of library, diplomacy, business, education and employment and the promotion of human rights. In this regard, Freeman (2007) mentions that we are witnessing a tremendous increase in the demand of English around the world. It is not only due to different changing demographics but also because of the trend towards globalization. Thus, the present world has been using the English language as a vehicle to transmit its developments, changes, innovations and many other things. As a result of the use of English, the world has become smaller and simpler than a larger cosmos. In similar vein, a policy statement issued by the United States Government has also clarified the growing interest and importance of the English language in the world. The statement states that English has become one of the most important world languages. The rapidly growing interest in English cuts across political and ideological lines because of the convenience of a lingua franca increasingly used as a second language in the important areas of the world (as cited in Gnyawali, 2010, p. 7). Because of the rapid changes in the field of science and technology, politics and the economic world, people seem to be forced to learn it. To make it clear, Holmes (2008) states that where new jobs are created by industrialization, they are of introduced by groups of using a majority group language with status often a world language such as English, Spanish or French. Globalization has also contributed to this trend.

In the context of Nepal, the use of English occupies important space in both the academic and non academic sectors. In this regard, Giri (2010, pp. 64-65) writes "the English language occupies an impeccable and indispensable place in the socio-economic system, and therefore, the drive for its learning is paramount...English is, therefore, socially, economically and educationally elevated higher than all other local languages". Regarding the position of English in Nepal, Awasthi (2003, as cited in Bhattarai and Gautam, 2007) states:

Nepal is providing education through six Universities about 1000 constituent and affiliated colleges, some 1500 higher secondary schools and 42100 schools of which 7154 are privately run and the rest are publicly run. English occupies a prominent position in the total education system in Nepal. (p. 32)

The number and interest of the people to study the English language either as formal education or in the form of informal education is increasing day by day. Regarding the space of English in school and college education, Sharma (2006) states that English has been offered as a compulsory subject from the primary level up to Bachelor level It is taught as an elective subject from the secondary level to the post graduate level. There is a provision of English as an optional subject from grade nine up to twelve under the curriculum of school education of Nepal. In case of higher education, English is offered as one of the elective subjects under the Faculty of Education (FoE) in B.Ed. and M.Ed. and under the Faculty of Humanities and Social Sciences (FoHSS) in B.A. and M.A. Similarly, English is taught for Specific Purposes (ESP) in the Faculty of Law, in the Institutes of Medicine, Engineering, Agriculture, Forestry, College of Banking and Financial Studies.

From both the global and local scenario of English, it can be stated that the English language plays 
an important role to enrich the status of several facets of the people of Nepal. The need, interest and importance of using English language in both specific and academic purposes have been realized to a great extent. More specifically, the use of English in school education system as a medium of instruction is an important issue to be investigated. Since EMI has been announced to be used mandatorily in the public secondary schools, teachers' perception, attitudes and readiness towards EMI has not been assessed and analyzed properly. Taking these facts into account, the study was conducted and this paper discusses the attitudes of teachers towards using English as a Medium of Instruction (EMI) in Public Secondary Schools of Ilam district.

\section{Review of Literature}

English language teaching in Nepal has made a history of about one and half a century. The formal introduction of English in Nepalese school education system is closely connected with the rise of Rana rule in the $19^{\text {th }}$ century. Regarding the historical inception of English in Nepal, Sharma (2006, p. 24) mentions, "So far the history of official history entry of the English language in Nepal is concerned, it is with the establishment of the first modern school, Durbar High School in 1954". At that time, the Durbar High School was established only for the children of Ranas to make them able to know and use the English language. The Ranas' children were taught English with the view in mind that the Rana Rule would have an easy access to British Empire. In a similar vein, Giri (2014) cites Madandhar (2002) and Vir (1998) as English was formally imported into Nepal during the Rana oligarchy and was seen as

a linguistic advantage favoring the ruling elites. Similarly, the development of English in Nepal is also closely connected with the spread of British Rule in India in the $19^{\text {th }}$ century. In the same way, the introduction of English in Nepalese education has some connection with the modern education system of India. It has been influenced by the education system of neighboring India. In this line, Bhattarai (2006, p. 11) writes:

Compared to the history of modern education in the neighboring India and the position that English has occupied there this period is quite short however this has left clear traces of its existence and gradual pace of development in Nepal too.

English in the higher education in Nepal was formally commenced after the establishment of Trichandra College in 1918 A.D. Before that, there was no college and university run formally to provide higher education to the people. But Giri (2010) claims with different evidence and writes that a landmark of English education, however, was the commencement of recruitment of Gurkha soldiers as a part of the famous Sugauli Treaty in 1815, the training of which took place in English. This was the beginning of English education in Nepal, though at a miniscule level. Moreover, after the establishment of Trichandra College, many other schools were established throughout the kingdom which further enhanced the spread of English teaching situation in Nepal however, there was not any significant pace for the English teaching situation until 1971. In this regard, Awasthi (2003, p. 22) mentions, "ELT in Nepal started in 1971 with the implementation of National Education System Plan (NESP) and that same year Tribhuvan University (TU) started B.Ed. program in English Education". From this it is inferred that English teaching situation 
spread establishment of Trichandra College and the formation NESP has significant space to bring English teaching situation in this state.

English has occupied important position in the education system of Nepal for years. The status of English in Nepal varies over time as per the fields in which it is used. Regarding the changing status of English Giri (2015) chronologically mentions that English has been labelled differently at different times throughout its history in Nepal. Initially it was adopted as a UN language. To be specific, in the beginning of the twentieth century, it was termed as a link language, a library language or even a reference language, in the middle of the century, it was taught and learned as a language of international communication, and in the 1980s and 1990s, English was considered an international language. The dawn of the twenty-first century has given English a new perspective - English as a Nepali language. In official discourse, however, it is still referred to as a 'foreign' language. Moreover, Giri (2014) writes that English in contemporary Nepal has been playing the role of lingua franca across various socioeconomic sectors and domains and it interacts with the local languages through code mixing and code-switching.

The school education system of Nepal has been running with two types of systems viz. government aided and privately run schools. The usage of English varies in these schools. The practice of English in the privately run schools is relatively much more than in government aided schools. In majority of the privately run schools, all subjects except for Nepali are prepared and taught in English. The medium of instruction in each class is also English. But the situation of the government aided schools is different. The learning materials are prepared in Nepali and the medium of instruction in majority of the classes is Nepali. This notices the variation in the use and practice of English in the instructional system of Nepal. In the same matter, Bhattaarai and Gautam (2007) suggested that there should not be such gap between the schooling systems of the same state and recommend the policy makers that they have to bridge the contrasting gap by establishing a meeting point. However, there is growing public craze towards the English language as the growing attraction of parents and students towards privately run education institutions in the country whether at the university level or the school level. Consequently, the role of English is significant and its use has been the quality parameters in the practice and delivery of quality instruction in the academic institutions.

\section{English as a Medium of Instruction (EMI): An Overview}

English language is viewed as the global language. It is taken as the most widely used means of communication. In this line, Pennycook (2001, p. 81) is of the opinion that English taking up such an important position in many educational systems around the world, it has become one of the most powerful means of inclusion into, or exclusion from further education, employment, or social positions. Moreover, English has been playing the role of global lingua franca to facilitate the process of communication between the people from diverse linguistic background. Along with the global importance of English, the notion of English as medium of instruction (EMI) has become a growing global phenomenon in the present day academia. 
Simply, the notion English as a medium of instruction (EMI) refers to the use of the English language in the classroom instruction where contents of various subjects are taught and delivered in English. In addition to this, the idea can be interpreted in terms of its practice in relation to different dimensions. For example, EMI means teaching all subjects as prescribed in the curriculum in English. Moreover, EMI is the use of English where professional courses are taught in English. In addition, EMI may mean giving lectures in English while assisting the students to learn the contents and matters of different subjects as offered in the schools or university curriculum. Dearden (2014, p.1) defines EMI as "The use of the English language to teach academic subjects in countries or jurisdictions where the first language (L1) of the majority of the population is not English". He further states that there is a fast-moving worldwide shift towards using English as a medium of instruction (EMI) for academic subjects such as science, mathematics, geography and medicine. EMI is increasingly being used in universities, secondary schools and even primary schools. This phenomenon has very important implications for the education of young people and policy decisions in non-Anglophone countries (Dearden, 2014). Thus, the medium of instruction has always been a key issue among educational institutions across the world especially in those nations who were once British colonies. Even though those nations have gained independence from the British rule yet its legacy still exists in one form or to the other. English language is one of the most prominent legacies left behind by the British Empire. Despite the unceasing global debate on English as the international lingua franca or as 'killer language' (Coleman, 2006), the adoption of English as a medium of Instruction (EMI) has been sweeping across the higher education landscape worldwide (Crystal, 2004). In this context, Nepal cannot remain in exception. Thus, the global spread of EMI has led the schools and universities of Nepal to adopt English as a medium of instruction. Since English is used to serve different functions in different settings. Among the various functions that we perform with English, EMI is one of the important uses of the English language in the academic context.

Many non-native English speaking countries have taken the notion (EMI) owing to the growing need for developing communicative competence in English that may fulfill the increasing demand for English language development. In the same way, the rise of English as a global lingua franca seems to be further forcing non-native speakers to learn and use the English language and many countries are trying to drastically overhaul their education system in favor of English in order to meet the challenge of global integration. In this very situation, Nepal, one of the developing countries, however it has not yet been able to sustain with the full effects of implementing EMI in the public schools and higher education institutions. The decision of introducing this huge change is made with no proper plans; however, some mere studies are on track (Sah, 2015). In the similar vein, as the instances of international practice of EMI, the countries, such as Ghana, Turkey and Rwanda have failed to continue EMI education because of the lack of educational infrastructure, teachers' proficiency in English, proper teacher education programs, and in-service professional development (Tylor, 2010). Nonetheless, EMI policy has also benefited many contexts, namely India, Pakistan and Spain, with suitable outcomes. They, however, used appropriate plans and principles (Marsh, 2006). Moreover, some countries initially failed to receive the set objectives and further developed plans that could lead to a successful implementation of EMI education. One of 
such contexts is a Ghanaian context where they introduced 'bilingual transitional literacy program' and 'Bridge to English' in order to build up suitable situations for the implementation of EMI education. EMI is therefore an interesting topic to discuss and is consequently receiving a huge attention from language policy researchers.

Similarly, Dearden (2014) reported some issues regarding the EMI practice globally include, the lack of EMI-qualified teachers and teaching resources, questions as to which subjects are to be taught through English medium, the age at which EMI starts, the lack of a standard level of English for EMI teachers, the role of the teacher, and the role of language centers and professional development. Since these are the global issues for implementing EMI, they seem to be identical in the Nepalese context. Thus, these very issues have paved the way to make an attempt to investigate this area in the context of Nepal.

Moreover, the choice and adoption of language of instruction in the multicultural and multilingual setting like Nepal is not a new phenomenon but it is a very difficult task. With reference to multilingual setting of various countries, Tsui and Tollefson (2003) put forward their view that choosing a language as a medium of instruction, which is part of the language-in-education policy, is not a novel issue as it has been discussed and studied worldwide, especially in the countries where multilingualism exists with diverse people and multi-ethnic groups such as Singapore, Malaysia, Indonesia, India, Canada, Hong Kong, etc. Thus, the selection of medium of instruction is sensitive in these countries because it profoundly impacts on political, economic, and sociolinguistic aspects of a country and may "lead to war and bloodshed" if ill-managed (Tsui \& Tollefson, 2003). So, the concerned authority should be very much careful in selecting and implementing the medium of instruction at any level.

\section{Methodology}

This paper has been prepared on the basis of a mixed method research carried out among the English language teachers teaching in twenty public secondary schools of Ilam district. The main objectives of the study were to find out the English language teachers attitudes towards English as a Medium of Instruction (EMI) and explore the challenges if any faced by the teachers while adopting EMI in the public schools. To fulfill these objectives, twenty secondary level English teachers were selected purposively. Questionnaire was used as the main tool for the collection of the data. For this, both close-ended and open-ended questions were set in a single sheet and distributed to draw data from the primary sources. Moreover, close-ended questions were used to obtain quantitative data and open-ended questions were asked to draw qualitative data from the respondent teachers. Then, data collected from the questionnaire were sorted, presented, analyzed and interpreted using both the quantitative and qualitative ways on the basis of nature of the data.

\section{Results and Discussion}

To investigate the English language teachers' understanding about the notion 'English as Medium of Instruction' (EMI), an open-ended question was asked to them. The question was "What do you understand by the notion ' English as a Medium of Instruction'(EMI)? In response to this question, teachers came up with a variety of ideas and opinions in relation to their own perception and experiences. In this regard, majority of the teachers were found aware of the notion of EMI and shared their view in relation to the daily teaching 
and learning activities. Though they responded this question from different angles and perspectives, the gist of their responses rested on the same ground focusing on the use of English language as a means of handling teaching and learning activities in the classroom. To justify the essence of their responses on the notion of EMI, some representative views and opinions of the teachers have been illustrated and discussed with brief annotation. Regarding the meaning of the notion of EMI, one of the teachers shared perception as, "English as a medium of instruction refers to the use of English as the language of teaching and learning during the classroom activities instead of using other languages". Moreover, highlighting the basic tenets of EMI two teachers shared similar view as "English as a Medium of Instruction constitutes the use of English as the language of handling instructional activities of any subject between students and teachers". In line with this view, another teacher set her/his idea as, "EMI is the English language used by the teacher to present his contents to the students in the classroom and the language of interaction between the teacher and students in the classroom teaching and learning. From the responses of some other teachers, it can be summarized that EMI is the use of English language in the classroom teaching and learning by both the teacher and students. It refers to the use of English language in the delivery of contents and practice of exercises and tasks during classroom teaching and learning by the teachers and learners.

From the above discussion, it is clear that almost all teachers were found aware of the basic concept of English as a medium of instruction. In this regard, majority of the teachers stated their view incorporating fundamental features and process of English as a medium of instruction in relation to their own instructional practices. Almost all of them perceived it as a means of delivering contents and proceeding interaction between teachers and students in the classroom instruction.

\section{Status of Implementing EMI in the Public Secondary Schools}

In order to find out the current status of the implementation of EMI in the public secondary schools, a closed-ended question, "Is there English as a medium of instruction implemented at your school?" was asked to the teachers. To respond to this question, they were given two options 'Yes' and 'No. In response, only 10 percent of the teachers responded with the option 'Yes'. It shows that very few public schools were found implementing English language as a medium of instruction to teach the subjects except English. On the other hand, 90 percent of them responded this query selecting the option 'No'. From this data, it can be stated that most of the public secondary schools have not been implementing English as a medium of instruction in teaching other subjects except English. On the whole, it can be summarized that the status of usage of English as a medium of instruction in the public schools is still considerable. Majority of the public secondary schools have not been handling instructional activities employing English as a medium of instruction effectively.

\section{Teachers' Views on EMI is Better than Other Media of Instruction}

This subheading mainly deals with the teachers' views on the assumption that EMI is better than other mediums of instruction to be used in the school. The main aim of this section was to find out how far they put emphasis on the use of EMI in comparison to other mediums of instruction in their daily teaching. To find out the teachers' view, a question "Do you agree that use of EMI is better than the other mediums 
of instruction in the schools?" was asked to them. To respond to this question, three options, i.e. 'Yes', 'Uncertain' and 'No' were given. In this regard, 65 percent of the teachers responded this question saying 'Yes' representing their strong agreement on the belief that use of EMI is better than the other mediums of instruction in the school. The data indicated that majority of the teachers have positive attitude towards using EMI in their instructional activities. They put more emphasis on the use of EMI than other mediums of instruction. Supporting this view, one of the teachers wrote "Because it builds up the students' strength in English and it becomes easy and enjoyable for them". This view asserts that the use of EMI helps to build the competence in English on the part of students. Likewise, another teacher also came up with positive view on this question and mentioned as "In my opinion, EMI is better than other mediums because, English language is used as the means of global communication. EMI makes our students able to communicate with the students from other countries using English. Similarly, EMI builds the competence and confidence to use English in various purposes".

On the other hand, 20 percent of the teachers went against the given statement with justifications. To defend the opinion, one of the teachers went on to say as "I don't agree with this belief and we should not ignore other languages in the name of using English only in the classroom teaching and learning. Medium of instruction should be used in consonance with the students' linguistic and cultural compositions in the classroom". Similar to this view, another teacher mentioned as," I don't think that EMI is better than other mediums of instruction because all languages are equally important. Other mediums can also be effective if they are implemented properly. So, medium of instruction should be used according to the classroom contexts". Regarding the same query, 15 percent of the teachers were found uncertain and ignorant. From this it can be said that some of the secondary level English teachers are not clear about value of EMI over other mediums of instruction. On the basis of analysis of the teachers' responses, it can be concluded that majority of the secondary level English teachers agreed with the belief that EMI is better than other mediums of instructions in our context. They put emphasis on the use of English as a medium of instruction in the public secondary schools in comparison to others. However, some few teachers were found negative about the view that EMI is better medium of instruction than other mediums.

\section{Challenges in Using EMI in the Class}

The main aim of this section was to find out teachers' perception about whether they have been facing challenges in employing EMI in the Nepalese EFL context. To find out their view, a question, "Do you agree that it is challenging to implement EMI in the Nepalese classroom?" was asked to them. To respond to this question, three options, that is, 'Yes', 'Uncertain' and 'No' were given. In response to this query, all the teachers showed their agreement choosing the option, 'Yes'. From this response, it can be said that it is challenging for the teachers to conduct teaching and learning activities employing English as a medium of instruction in the EFL classroom. To support their view, teachers mentioned a variety of causes which impeded them to implement EMI effectively. To quote the view of a teacher, "It is difficult for the Nepalese English teachers to use EMI effectively in the Nepalese classes because there is very weak exposure to English among the students. Students in the class are from diverse linguistic and cultural 
backgrounds" Here, the teacher have faced challenges to implement EMI due to the weak exposure to English and diverse linguistic and cultural standpoints of the students in the class. In the same way, four teachers were found sharing nearly same opinion that it is challenging task for the majority of the Nepalese English teachers to implement EMI in their classroom teaching due to the interference of students' mother tongues since students are from different ethnic and linguistic communities. Here, it is stated that students' mother tongue interference is the main cause to create difficulty in the smooth and effective use of EMI in the Nepalese EFL classrooms.

From the analysis of the teachers' responses, it can be interpreted that public schools' English teachers have been facing various challenges in using English as a medium of instruction like students' weak exposure to English language, mother tongue interference in the classroom, poor competence of students in English, lack of support and encouragement from the parents and society and no motivating environment for the teachers and schools are not resourceful and well facilitated.

\section{Teachers' Experience of Training and Workshops on EMI}

This heading was attempted to explore the extent of experience of the teachers attending various training and workshops regarding the issue of EMI. In this purpose, teachers were provided a closed ended question including two options, that is, 'Yes' and 'No' to respond. Moreover, they were also asked to mention their remarkable experience if they had such incidents of participating in any academic events on the issue of EMI. In response to this question, all the teachers responded with the option 'No'. As they replied this question negatively, they did not mention about their experience. It means they did not have any remarkable experience of attending the EMI focused training, workshops and webinar to be implemented in their regular teaching and learning practices. From the analysis of the data, it can be concluded that the teachers of the public schools have not had much notable involvement and practice in the EMI focused events and functions. They did not get opportunity to participate in the training, workshops, and conferences about the practice of EMI.

\section{Institutional Encouragement to the Teachers Employing EMI in the School}

In this part, teachers were asked whether they have been encouraged by their institutions for employing and enhancing EMI based teaching and learning activities. To draw their response, they were asked a question, "Does your institution encourage you to use English as a medium of instruction?" To respond this query they were provided two options as 'Yes' and 'No' for them. In response to this question, teachers came up with mixed response. For this, majority of the teachers, that is, 90 percent, responded that there is no encouraging environment in their schools for practicing EMI supported instructional activities in their regular pedagogy. In this regard, teachers also shared their bitter experience that there is no English speaking environment around their school premises. Though interested teachers wanted to communicate in English with each other, other made them compelled to use Nepali language around the school area. Moreover, they shared that their institution did not conduct any interaction program talking about EMI to be implemented in the classroom. As they mentioned that although they tried a lot to change the way of instruction in the schools, they could not do it due to the lack of support, cooperation and collaboration from 
the concerned stakeholders. Regarding the same issue, 15 percent of them stated that they are encouraged by their institutions for using EMI in their instructional activities. As the evidence, it is noteworthy to mention the experience of a teacher. She says "My school has really been encouraging in creating English friendly environment. School management committee, school administration, teachers and parents are cooperating to flourish and conduct instructional activities using English as a medium of instruction. Our school has been running with fully English medium instruction up to grade seven. We are getting appreciation from all stakeholders". From this data too, it can be summed up that teachers are not much encouraged by their institutions and concerned authority for adopting EMI based instructional activities in their schools. There is not favorable environment for the teachers to conduct EMI based teaching and learning activities due to the lack of required resources.

\section{Benefits of Employing EMI to the Teachers}

In order to draw the teachers' opinions on the benefits of using EMI for their own pedagogical and professional endeavors, they were given an open ended question. The question was "What, in your opinions, are the benefits of using EMI for the teachers?" In response to this question, teachers came up with a variety of ideas and opinions. They mentioned a number of benefits relating to their personal, pedagogical and professional fields. As they stated that EMI helps them to enhance competence in English language usage and use and it is the real exhibition of the competence of the teachers' English. Similarly, teachers opined that EMI makes the teachers inquisitive and explorative in their own pedagogical and professional issues. EMI plays pivotal role in their professional development. They further mentioned other benefits that EMI is the prime means to the teachers for the reflective practices with the help of which teachers become able to communicate in English globally. Teachers are motivated to access worldly available resource materials to be used in their pedagogical and professional lives. Regarding the same concern, some other teachers responded that EMI helps the teachers to manage and conduct ICT supported instruction in the schools in this technology and they can enhance and expand their regular pedagogical and professional practices. From all these points, it has been clear that all the public secondary level teachers have perceived use of EMI positively. They are well aware of the importance of the EMI in their own pedagogical and professional practices.

\section{Conclusion and Implications}

The paper has presented and discussed the results of a survey study carried out among the 20 secondary level English teachers of public schools from Ilam district. It investigated the attitudes of teachers towards using English as a medium of instruction in the public schools and explored the various problems and challenges faced by the teachers while adopting EMI in the public schools. The findings of the study showed that teachers of public schools were found aware of the basic concept of the notion of English as a medium of instruction. They were found positive in implementing EMI in conducting their daily teaching and learning activities. In the same way, majority of the teachers mentioned that they would like to employ EMI in their instructional activities over teaching with learners' mother tongue. Although they showed positive attitudes towards using EMI, the real status of implementation was not found satisfactory. It means that a few public secondary schools 
were found implementing EMI in their instructional activities. In addition to this, it can also be concluded that public schools' teachers cannot adopt EMI effectively and efficiently in their daily classes due to the problems and challenges like students' weak exposure to English language, mother tongue interference in the classroom, poor competence of students in the English language, lack of support and encouragement from the parents and society and no motivating environment for the teachers, lack of clear plan and policy regarding the usage of EMI and schools are not resourceful, and well facilitated. Based on these findings, it is recommended that there should be conducive and encouraging environment in the public schools for the teachers to encourage them for adopting EMI in the class. The schools should be made resourceful and well equipped with modern technologies. Moreover, the teachers should be made sound with pedagogically and professionally. The concerned authority should provide the opportunities to them to take part in the trainings, seminars and workshops on EMI.

Despite the new insights gained from this study, a number of limitations need to be addressed. Firstly, this was a small study among twenty English teachers, and hence the findings may lack generalizability. It can also be conducted in the larger scale in the future. Secondly, this study primarily investigated teachers' perception on EMI but it could explore the extent of real practices of EMI in their instructional activities. So, it may be advantageous to look at the practices of EMI in the public secondary schools in another study.

\section{References}

Awasthi, J. R. (2003). Teacher education with special reference to English language teaching in Nepal. Journal of NELTA, 8 (1), 17-27.

Bhattarai, G. R. \& Gautam, G. R. (2007). The proposed ELT survey: Redefining status and role of English in Nepal. Journal of NELTA,12 (1), 1-2.

Bhattarai, G. R. (2006). English teaching situation in Nepal: Elaboration of the theme for panel discussion in the $40^{\text {th }}$ TESOL conference. Journal of NELTA,11 (1), 1-2.

Coleman, J. A. (2006). English-medium teaching in European higher education. Language Teaching, 39 (1), 1-14.

Crystal, D. (1990). The English language. London: Penguin Books.

Dearden, J. (2014). English as a medium of instruction - a growing global phenomenon: phase 1 Interim report, 3-6. Retrived from www.britishcouncil.org/sites/ britishcouncil.uk2/files/english_as_a_ medium_of_instruction.pdf

Freeman, D. L. (2007). Teaching and learning English: From ideology to empowerment. Journal of NELTA, $12(1), 1-2$.

Giri, R. A. (2015). The many faces of English in Nepal. Asian Englishes, 17 (2), 94-115. doi: 10.1080/13488678.2015.1003452

Giri, R. A. (2014) Changing faces of English: Why English is not a foreign language in Nepal. Journal of World Languages, 1 (3), 192-209. doi: 10.1080/21698252.2014.989643

Giri, R. A. (2010). English language teachers' resource centre: A model for developing contexts. Journal of NELTA, 15 (1 \& 2), 64-76. 
Gnyawali, B. D. (2010). The need of English in public administration. Unpublished M.Ed. Thesis. Tribhuvan University, Kathamndu, Nepal.

Holmes, J. (2008). An introduction to sociolinguistics. London: Pearson Longman.

Marsh, D. (2006). English as medium of instruction in the new global linguistic order: Global characteristics, local consequence, METSMaC. Retrived from https://pdfs.semanticscholar.org/ ebc2/a8d7326ccd4000792e38dd9e7fdfefd35bae.pdf

Pennycook, A. (2001). English in the world/the world in English. In Burns, A. \& Coffin, C. (Eds.), Analyzing English in a global context: A reader (pp. 78-92). London; New York: Routledge.

Phillipson, R. (2007). Linguistic imperialism. New York: Oxford University Press.

Sah, P. K. (2015). English medium instruction (EMI) in Nepalese education: potential or problem? [Blog article]. ELT CHOUTARI. Retrieved from $<$ http://eltchoutari.com

Sharma, K. C. (2006). English in Nepal from the past to present. Journal of NELTA, 11 (1), 1-2.

Taylor, S. K. (2010). MLE policy and practice in Nepal: identifying the glitches and making it work. In K. Heugh, \& T. Skutnabb-Kangas (Eds.), Multilingual education works: From the periphery to the centre (pp. 204-223). New Delhi: Orient Black Swan.

Tsui, A. B. \& Tollefson, J. W. (2003). The centrality of medium of instruction policy in sociopolitical processes. In A. B. Tsui \& J. W. Tollefson (Eds.), Medium of instruction policies: Which agenda? Whose agenda?(pp. 1-20). New Jersey: Lawrence Erlbaum Associates Publishers.

\section{Krishna Kumar Khatri is a Lecturer of English Education at Tribhuvan} University, Nepal. He has been teaching to the M.Ed. and B.Ed. students in Mahendra Ratna Multiple Campus, Ilam for about a decade. To his credit, about a dozen of academic articles have been published in different national and international journals. His areas of interests include ELT methodology, research methodology, ICT in language education and Teacher identity 